\title{
TINJAUAN PERAN KOMUNIKASI KELUARGA PADA KINERJA PUBLIC RELATIONS MELALUI KONTEN LAMAN RESMI MEDIA DARING KPPPA
}

\author{
Family Roles Communication Review on Public Relations Activity \\ through KPPPA's Official Websites
}

\author{
Rustono Farady Marta $^{1, *)}$, Joshua Fernando, Laurencia Steffanie Mega Wijaya Kurniawati \\ ${ }^{1}$ Program Studi Magister Ilmu Komunikasi, Fakultas Ilmu Sosial dan Humaniora, Universitas Bunda Mulia, Jakarta 14430, Indonesia \\ ${ }^{*}$ E-mail: rmarta@bundamulia.ac.id

\begin{abstract}
This study aims to look at the KPPPA's communication through its regime website in reducing readers about the role of caregiving and the role of control in the family. This study uses the theory of the role of family communication from Beth A. Le Poire. The study was conducted from May to August 2019 using a systematic content analysis method from Berelson. The findings of this study are that KPPPA has produced articles on its official website in a balanced manner regarding the role of caregiving and the role of control in the family, but the KPPPA official website itself has not been able to capture a wide audience. It can be concluded that KPPPA's public relations has been right in producing content regarding family communication.
\end{abstract}

Keywords: family roles communication, online media, public relations, systematic content analysis

\begin{abstract}
ABSTRAK
Penelitian ini bertujuan melihat komunikasi KPPPA melalui situs resimnya dalam mengeduksi pembaca tentang peran pengasuhan dan peran kontrol dalam keluarga. Penelitian ini menggunakan teori peran komunikasi keluarga dari Beth A. Le Poire. Penelitian dilakukan dari Mei hingga Agustus 2019 dengan menggunakan metode analisis isi sistematik dari Berelson. Temuan dari penelitian ini adalah KPPPA telah memproduksi artikel-artikel di situs resminya secara seimbang mengenai peran pengasuhan dan peran kontrol dalam keluarga, namun situs resmi KPPPA sendiri belum dapat menjaring pembaca secara luas. Dapat disimpulkan bahwa humas KPPPA telah tepat dalam memproduksi konten mengenai komunikasi keluarga.
\end{abstract}

Kata Kunci: peran komunikasi keluarga, media daring, humas, analisis isi sistematik

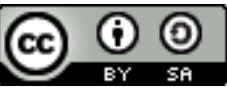

Content from this work may be used under the terms of the Creative Commons Attribution-ShareAlike 4.0 International License.. Any further distributionof this work must maintain attribution to the author(s) and the title of the work, journal citation and DOI.

Published under Department of Communication and Community Development Science, IPB University

ISSN: 1693-3699 |EISSN: 2442-4102 


\section{PENDAHULUAN}

Manusia selalu menjalin relasi dengan manusia lain (Wahjudi, 2018), salah satu kelompok relasi yang dimiliki manusia yakni keluarga. Keluarga memiliki posisi yang penting karena dapat menentukan perilaku dan memengaruhi komunikasi antar anggota keluarga. Keluarga merupakan suatu unit dimana orang-orang didalamnya saling mengenal dan senang satu sama lain (Yuningsih, 2005). Keluarga juga disebut sebagai tempat yang paling awal dan efektif untuk menjalankan fungsi pendidikan dalam menanamkan kejujuran, kedisiplinan, dan rasa tanggungjawab sebagai unsur dari karakter anak (Suarmini et al., 2016). Peran keluarga yang baik adalah menjadi wadah yang tepat bagi perkembangan anggota keluarga secara wajar, sehingga menjadi sebuah keluarga harmonis dan bahagia.

Thomas Lickona mengatakan bahwa secara umum orang-orang memandang keluarga sebagai sumber pendidikan moral yang paling utama bagi anak-anak. Hubungan antar orang tua dan anak dipengaruhi oleh emosi yang menyebabkan anak dapat merasakan perlindungan, kasih sayang, dan dihargai oleh keluarga, sehingga dapat membentuk karakter seorang anak. Suasana keluarga tanpa kekerasan adalah salah satu bentuk yang sangat efektif untuk membuat seorang anak merasa nyaman, damai, dan tentram apabila berada di rumahnya. Dampak dari perasaan nyaman tersebut adalah emosi anak yang stabil sehingga karakter yang baik akan terbentuk (Nihayah, 2018). Data menunjukkan bahwa kekerasan dalam rumah tangga terus meningkat dari tahun ke tahun (Pramudya, 2014), namun saat ini kekerasan yang terjadi dalam rumah tangga tidak hanya berfokus pada kaum lemah, yaitu perempuan, tetapi juga pada anggota keluarga lainnya.

Pola komunikasi keluarga adalah komunikasi yang terjadi dalam keluarga dimana sumber komunikasi adalah orang tua. Pola komunikasi keluarga dimaksudkan sebagai cara untuk menjalankan fungsi sosialisasi dalam keluarga yang berkenaan dengan penanaman nilai dan norma kepada anak ataupun anggota keluarga (Sari et al., 2010). Komunikasi keluarga mewakili proses pembentukan oleh orang tua terhadap sikap, perilaku, dan pandangan anak-anak terhadap dunia (Campbell \& Kachik, 2017). Melalui komunikasi keluarga, norma dan etika yang dicerminkan dari sikap, perilaku, dan pandangan anak-anak dapat dipertahankan karena adanya proses pewarisan nilai-nilai melalui keluarga dari generasi ke generasi (Satya Yoga et al., 2015). Pembentukan sikap, perilaku, dan pandangan atas dunia didasari oleh komunikasi yang dibangun dalam sebuah ikatan keluarga, baik itu pertukaran pengalaman, ide, dan persepsi (I. Satriani, P. Muljono, 2011). Pengasuhan anak dapat diterapkan tidak terlepas dari pemaknaan masing-masing individu terhadap pengasuhan itu sendiri. Pengasuhan anak bukan hanya perkara fisik atau sesuatu hal yang dapat dilihat mata. Lebih dari itu seluruh media memberikan pendidikan baik secara psikis dan sosial dalam bentuk kasih sayang, perhatian, komunikasi, pembelajaran, dan kontrol (Yulion, 2013).

Penelitian ini menggunakan Family Roles Communication Theory dari La Poire. Teori ini mendefinisikan keluarga sebagai kelompok sosial terkecil yang di dalamnya terdiri dari ayah, ibu, dan anak yang masing-masing memiliki peran di dalamnya. Keluarga adalah sebuah kelompok primer sosial yang memiliki hubungan tatap muka dengan ikatan emosional yang kuat antar anggota. Sebuah keluarga umumnya memiliki tugas kehidupan berkeluarga seperti; sosialisasi, pengasuhan, pengembangan dan dukungan emosional serta finansial (Evelyn, 2018: 4).

Kajian budaya merupakan hal terpenting dalam komunikasi (Kriyantono \& Sa'diyah, 2018) Dissanayake menyebutkan bahwa budaya tanpa komunikasi tidak dapat bernapas. Proses komunikasi secara menyeluruh terjadi dalam konteks budaya. Proses komunikasi memahami komunikan dan upaya menciptakan kesamaan latar belakang antara komunikator dan komunikan. Pemahaman terhadap karakter budaya ini juga perlu dilakukan oleh praktisi public relations atau kehumasan sebagai komunikator yang mewakili organisasi sebagai manajer komunikasi. Public relations adalah proses manajemen komunikasi antara lembaga dan publiknya (Kriyantono \& Sa'diyah, 2018). Pandangan Philip Kitchen "Public relations pada dasarnya adalah sebuah fungsi komunikasi namun dengan penekanan pada sifat dua arah dari proses komunikasi, berkaitan dengan cara membangun dan memelihara saling pengertian dan goodwill antara organisasi dan kelompok orang tertentu melayani sebagai fungsi intelijen, menganalisis dan menginterpretasikan kecenderungan dan isu lingkungan yang mungkin mengandung konsekuensi bagi suatu organisasi dan para pemangku kepentingan" 
(Kriyantono \& Sa'diyah, 2018), ada prakteknya public relations akan melakukan koordinasi dan kerjasama dengan bagian lain dalam organisasi guna menjalankan aktifitas komunikasi untuk mencapai tujuan yang telah ditetapkan. Pengertian ini menekanan bahwa public relations sebenarnya merupakan bagian penting dalam organisasi yang mengelola dan bertanggung jawab terhadap keberhasilan dan kegagalan tindakan komunikasi melalui situs resmi dari organisasi.

Google Consumer Behaviour menyatakan 50\% masyarakat Indonesia dengan populasi 265,4 juta memiliki pola hidup serba digital native dimana Internet sudah dijadikan bagian dari hidup masyarakat (Supratman, 2018 47-48). Asosiasi Penyelenggara Jasa Internet Indonesia (APJII) memaparkan 143,26 jiwa penduduk Indonesia pada tahun 2017 menggunakan Internet. Terkait fakta tersebut, masyarakat seringkali mencari sebuah informasi yang cepat diperoleh dan memiliki kredibilitas, baik informasi mengenai peristiwa terbaru ataupun sebuah organisasi. Masyarakat akan lebih memberi kepercayaan lebih pada Situs resmi resmi pada organisasi, ini pula kegunaan situs resmi yakni memberikan layanan standar kepada publik dan dapat menyampaikan berbagai hal yang menjadi kebutuhan masyarakat yang kian meningkat khususnya pada teknologi (Wiratmo et al., 2017). Media situs resmi merupakan media komunikasi yang dapat menyampaikan pesan visual dan audio secara interaktif yang dapat menggabungkan unsur teks, gambar (foto dan film) dan suara sebagai satu kesatuan yang disebut dengan multimedia (Nugroho \& Saleh, 2012). Muncul sebagai platform yang menjadikan distribusi informasi dilakukan tanpa halangan spasial dan media ini mempunyai ciri yang bisa diakses dari manapun sepanjang sang pengguna atau pembaca memiliki jaringan internet yang akan mengantarkannya ke ranah World Wide Web (WWW) (Rahmawati \& Anindhita, 2016:730). Peneliti ini menganalisis situs resmi Kementerian Pemberdayaan Perempuan dan Perlindungan Anak (KPPPA) dengan menggunakan metode analisis isi.

Penelitian ini menggunakan prinsip analisis isi sistematik Berelson (Hidayat, 2015) yang meneliti secara keseluruhan data yang diperoleh dari laman siaran pers yang menggunakan peran keluarga didalamnya periode Mei hingga Agustus 2019. Hasil dari menganalisis 7 laman siaran pers tersebut akan dibagi berdasarkan kategori pada teori family roles communication perspektif Beth A. Le Poire kemudian di reduksikan menjadi sebuah data yang akurat menurut perhitungannya, data tersebut dapat menunjukkan bagaimana strategi budaya kehumasan KPPPA ingin menjalankan fungsinya sebagai fasilitator bagi keluarga Indonesia dalam lingkup orang tua membimbing anaknya. Peran orang tua sangat penting bagi anak, serta sangat membekas bagi kehidupan anak kedepannya (Sasongko \& Marta, 2018).

Kementerian Pemberdayaan Perempuan dan Perlindungan Anak (KPPPA) merupakan bagian dari Kabinet Kerja yang melaksanakan tugas dan fungsi sesuai dengan Peraturan Presiden Nomor 59 Tahun 2015 tentang Kementerian Pemberdayaan Perempuan dan Perlindungan Anak dan Keputusan Presiden Nomor 121/P Tahun 2014 tentang Pembentukan Kementerian dan Pengangkatan Menteri Kabinet Kerja. Penyusunan tujuan, sasaran, strategi, kebijakan, dan program KPPPA berpedoman pada Rencana Pembangunan Jangka Menengah Nasional (RPJMN) Tahun 2015-2019 (Peraturan Presiden Nomor 2 Tahun 2015) yang merupakan penjabaran dari visi, misi, dan agenda (Nawacita) Presiden/Wakil Presiden Republik Indonesia. Sesuai dengan RPJMN 2015-2019 tersebut, visi pembangunan nasional tahun 2015-2019 adalah: "Terwujudnya Indonesia Yang Berdaulat, Mandiri, dan Berkepribadian Berlandaskan Gotong-Royong" (Perdana, 2018). KPPPA selaku lembaga ikut berkontribusi dalam mengedukasi masyarakat melalui media sosial (Marta et al., 2019), serta membangun komunikasi yang ideal di dalam keluarga, sehingga menciptakan anggota keluarga yang memiliki pertumbuhan kepribadian baik dan mandiri, peduli terhadap lingkungan sekitar, dan yang terpenting peduli terhadap negara Indonesia. KPPPA, melalui situs resminya, turut serta berkontribusi dalam mengedukasi masyarakat melalui media digital (Agung et al., 2019).

Family roles communication atau komunikasi peran keluarga menurut Beth A. Le Poire dibagi menjadi dua kategori penelitian analisis isi yaitu: (1) peran pengasuhan (nurturing roles) mencakup penyedia, yang memasok sumber daya yang diperlukan untuk memungkinkan jenis kegiatan yang diperlukan untuk mendorong pertumbuhan dan pengembangan. Pengasuhan keluarga sesuai dengan pola yang dikemukakan oleh Le Poire yakni provider; nurturers; development expert (social, emotional, and physical); health care provider. Dalam penelitian ini, setiap kata yang menggambarkan dalam pola pengasuh (nurturing roles) seperti kasih sayang, perlindungan, 
pemenuhan kebutuhan, perawatan fisik, dan mental emosional yang muncul dalam peran keluarga akan masuk di kategori pengasuhan. (2) peran pengendalian (controlling roles) yakni upaya membatasi pilihan perilaku anggota keluarga untuk memastikan pencapaian tujuan yang diharapkan dalam masing-masing keluarga dalam mengontrol peran dapat dilakukan melalui pola behavior control; decision making; boundary maintenance; financial organization. Dalam penelitian ini, setiap kata yang menggambarkan dalam pola kontrol (controlling roles) seperti pemberdayaan, pembatasan, peraturan, pengaturan, dan organisasi yang muncul dalam peran keluarga akan masuk di kategori kontrol.

Peran pengasuhan dan peran kontrol menjadi dimensi besar untuk menganalisis penerapan peran komunikasi keluarga pada laman siaran pers di situs KPPPA periode Mei hingga Agustus 2019. Penelitian ini melihat strategi kebudayaan humas yang ditonjolkan serta komunikasi yang dibangun untuk mengedukasi masyarakat dalam setiap postingan pada laman siaran pers sebagai informasi yang secara resmi membawakan citra kredibilitas KPPPA.

Tabel 1. State of the art

\begin{tabular}{|c|c|c|}
\hline Judul & Sumber & Celah Riset \\
\hline $\begin{array}{l}\text { Situs resmi Pemerintah Daerah } \\
\text { Sebagai Sarana Online Public } \\
\text { Relations }\end{array}$ & $\begin{array}{l}\text { (Wiratmo et al., } \\
\text { 2017) }\end{array}$ & Ketiga penelitian terdahulu berfokus \\
\hline $\begin{array}{l}\text { Kondisi Terkini Perkembangan } \\
\text { Pelaksanaan E-Government di } \\
\text { Indonesia: Analisis Situs resmi }\end{array}$ & $\begin{array}{ll}\text { Yunita } & \& \\
\text { Aprianto, 2018) }\end{array}$ & $\begin{array}{l}\text { Kepada analisis teknis mengenal } \\
\text { penggunaan situs resmi dan kebepihakan } \\
\text { media daring sebagai wadah informasi bagi }\end{array}$ \\
\hline $\begin{array}{l}\text { Media dan Keberagaman: } \\
\text { Analisis Pemberitaan Media } \\
\text { Daring Seputar Pemilihan } \\
\text { Kepala Daerah DKI Jakarta } \\
\text { Ahmad }\end{array}$ & (Junaidi, 2017) & $\begin{array}{c}\text { berfokus kepada analisis isi konten peran } \\
\text { keluarga pada media daring situs resmi } \\
\text { milik institusi KPPPA }\end{array}$ \\
\hline
\end{tabular}

Wiratmo et al. (2017) menemukan model pemanfaatan situs resmi pemerintah daerah sebagai sarana online public relations. Yunita \& Aprianto (2018) mengemukakan hasil assessing e-goverment menunjukkan bahwa sejumlah 83 pemerintah daerah masih dalam tahap pertama (persiapan), 341 dalam tahap kedua (pematangan), 115 dalam tahap ketiga (pemantapan), dan 4 pemerintah daerah yang telah masuk ke dalam tahap keempat (pemanfaatan). Junaidi (2017) Menemukan sejumlah pelanggaran kode etik jurnalistik dalam berita-berita seputar Pilkada Jakarta di media daring, terutama terkait penggunaan isu agama. Penelitian ini mempunyai perbedaan yang berfokus pada analisis isi konten situs resmi mengenai peran keluarga sehingga sesuai dengan visi dan misi institusi KPPPA.

Penelitian ini bertujuan untuk melihat komunikasi KPPPA mengenai keseimbangan peran kontrol dan peran pengasuhan yang ideal dalam keluarga pada lama siaran pers dari situs resmi KPPPA.

\section{METODE}

Penelitian ini disusun berdasarkan kerangka pemikiran yang berpijak kepada teori Family Roles Communication dari Le Poire. Peneliti menganalisis konten situs resmi KPPPA dari tujuh laman siaran pers pada kurun waktu Mei-Agustus 2019 yang menonjolkan peran keluarga. Penelitian ini menggunakan metode analisis isi sistematik dari Berelson.

Pengamatan dilakukan selama 4 bulan untuk mengamati perubahan apa yang signifikan dilakukan pada media daring situs resmi KPPPA dengan adanya peralihan kebijakan dari hanya perlindungan bagi wanita menjadi pemberdayaan perempuan dan perlindungan terhadap anak.

Riset ini menggunakan paradigma positivistik dengan pendekatan kuantitatif melalui metode analisis isi (content analysis) untuk memahami pendekatan budaya dalam praktek kehumasan. Analisis isi atau konten didefinisikan menurut Berelson (1952) sebagai suatu metode untuk mempelajari dan menganalisis komunikasi secara sistematik, objektif, dan kuantitatif terhadap pesan yang tampak. (Edi Setyawan dan Zainal Arifin, 2016). 
Ada beberapa prinsip analisis isi yang digunakan dalam penelitian ini, yaitu: prinsip sistematik; prinsip objektif; prinsip kuantitatif; prinsip isi yang nyata (Setiadi, 2010). Fungsi dari analisis isi adalah memberikan kesempatan pada peneliti untuk menguji teori dalam kerangka menambah pemahaman akan data. Analisis isi menurut Cavanagh (1997) memungkinkan penyaringan data menjadi kategori konten yang sama, maka ia memiliki arti atau makna yang sama pula (Kumalaningtyas \& Sadasri, 2018 : 63). Tujuan dari analisis isi dalam riset ini adalah untuk memperoleh deskripsi atau penjelasan yang padat dan luas tentang sebuah fenomena. Metode analisis isi data kuantatif seperti melihat persentase penonjolan yang memunculkan bagaimana strategi media konstruksi budaya (Marta, 2003) yang ingin ditampakkan oleh humas KPPPA melalui postingan situs resmi resmi laman siaran pers. Dalam formula Holsti, angka reliabilitas minimum yang ditoleransi adalah $70 \%$ atau 0,7. Apabila berada diatas atau sama dengan angka tersebut maka alat ukur dinyatakan reliabel (Handayani et al., 2015).

\section{HASIL DAN PEMBAHASAN}

Penelitian ini menggunakan pendekatan kuantitatif, analisis isi sistematik Berelson (Hidayat, 2015) yakni mengambil secara keseluruhan data. Penelitian ini ingin melihat penonjolan strategi budaya kehumasan yang muncul di dalam situs resmi KPPPA dengan jumlah 7 postingan di laman siaran pers periode Mei - Agustus 2019 dalam menonjolkan konten yang mengedukasi keluarga (orang tua dan anak) Indonesia. Dengan memilah menurut kategorinya yakni nurturing roles diinisialkan N dengan pola (1) provider; (2) nurturers; (3) development expert (social, emotional, and physical); (4) health care provider. Dan controlling roles di inisialkan C dengan pola (1) behavior control; (2) decision making; (3) boundary maintenance; (4) financial organization. Untuk melihat dominan antara kedua kategori tersebut, peneliti menghitung menggunakan rumus :

Nurturing Roles $=$ Jumlah kata dalam kategori / Jumlah kata deskripsi x 100\%

Controlling Roles $=$ Jumlah kata dalam kategori / Jumlah kata deskripsi x 100\%

Buat tabel yang memberikan contoh pengkodean, yaitu kata yang termasuk ke dalam kategori Nurturing yang seperti apa, yang Controlling seperti apa.

Buat tab

\begin{tabular}{|l|l|}
\hline Nurturing Words & Controlling Words \\
\hline $\begin{array}{l}\text { Perlindungan, kesehatan, mendidik, pendampingan, } \\
\text { edukasi, pembangunan fisik, perkembangan } \\
\text { emosional. }\end{array}$ & $\begin{array}{l}\text { Aturan, dampingi, pedoman, tatanan, sopan - } \\
\text { santun, monitoring, pengawasan }\end{array}$ \\
\hline
\end{tabular}

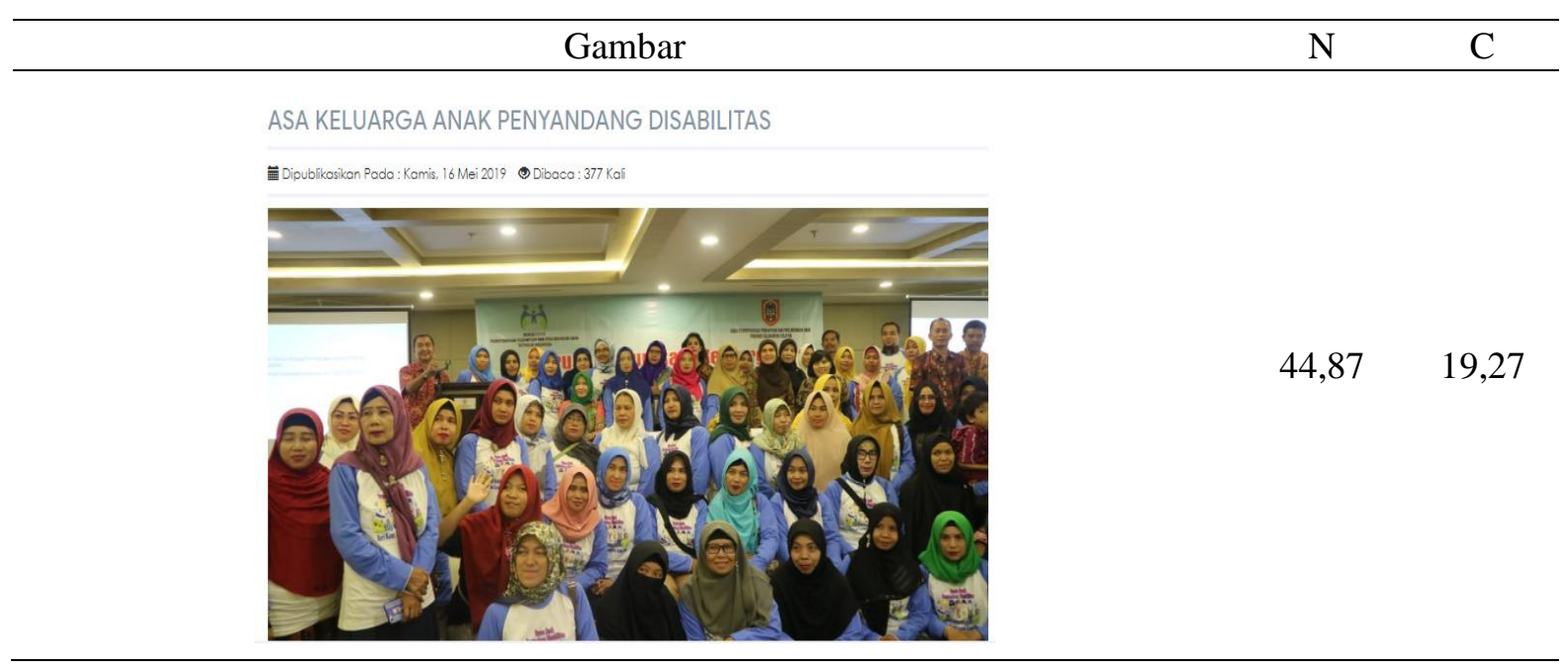

Gambar 1. Artikel Pertama 
Siaran pers pada 16 Mei 2019, dengan judul "Asa Keluarga Anak Penyandang Disabilitas" dibaca 378 kali. Memiliki 664 total kata yang terdiri atas 238 kata tidak dalam kategori, 298 kata termasuk dalam kategori nurturing roles, dan 128 kata termasuk dalam kategori controlling roles.

"Orang tua sebagai unsur terdekat Anak dan keluarga memiliki kewajiban dan tanggung jawab tinggi atas perlindungan anggota keluarga mereka. Pemerintah ikut berperan terutama terkait pelaksanaan kebijakan demi pemenuhan hak dan perlindungan terbaik bagi Anak Penyandang Disabilitas. terdapat beberapa kebijakan terkait Anak Penyandang Disabilitas antara lain: kesehatan, sosial, dan pendidikan. Misalnya bagaimana ketika Anak Penyandang Disabilitas tersebut memerlukan layanan dari Badan penyelenggara Jaminan Sosial (BPJS)."

Dari kutipan ini dapat dilihat bahwa ditonjolkannya peran keluarga kategori nurturing roles pola provider yakni peran orang tua sebagai pemelihara; pola nurtures, yakni perawatan, dan dukungan dari orang tua terhadap anak; pola Development Expert dalam artikel ditampakkan kesetaraan anak penyandang disabilitas tentang kewajiban memperoleh pendidikan.

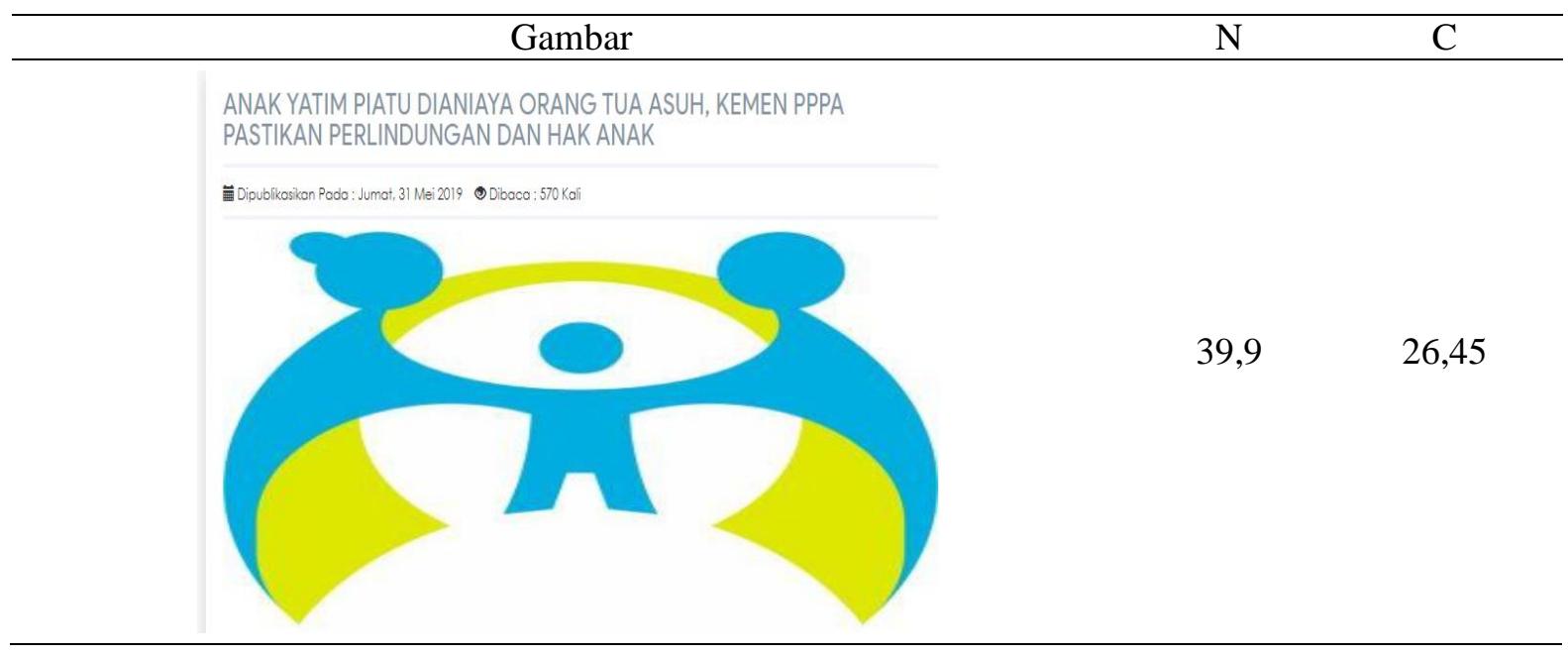

Gambar 2. Artikel Kedua

Siaran pers pada 31 Mei 2019 dengan judul "Anak Yatim Piatu Dianiaya Orang Tua Asuh, Kemen PPPA Pastikan Perlindungan Dan Hak Anak" dibaca 574 kali. Memiliki 654 total kata yang terdiri atas 220 kata tidak dalam kategori, 261 kata termasuk dalam kategori nurturing roles, dan 173 kata termasuk dalam kategori controlling roles.

"Menteri Pemberdayaan Perempuan dan Perlindungan Anak (PPPA), Yohana Yembise menurunkan tim untuk meninjau langsung proses pendampingan dan penyelesaian kasus yang dilakukan oleh pemerintah daerah setempat serta memastikan agar anak terlindungi dan tetap terpenuhi hak-haknya. Ananda CA harus mendapatkan perlindungan dari tindakan kekerasan yang selama ini dialaminya. Pelaku harus segera ditemukan dan diproses secara hukum. Kita semua perlu bekerjasama untuk kembali memulihkan kondisi CA baik fisik maupun psikologisnya, KPPPA sebagai kementerian yang bertugas untuk memenuhi dan menjamin perlindungan anak akan mengawal kasus ini hingga tuntas. kasus ini dengan mempertimbangkan kepentingan terbaik bagi anak".

Dari kutipan ini, dapat diketahui bahwa pengambilan alih peran pengasuhan orang tua terhadap anak terkait perlindungan, dan pendampingan telah diambil alih oleh KPPPA, dan peran kontrol telah diambil sekaligus dengan mengawal kasus kekerasan terhadap anak ini ke jalan hukum. KPPPA mengeluarkan program yang dianggap unggulan yaitu Perlindungan Anak Terpadu Berbasis Masyarakat (PATBM) yang mana program ini diharapkan dapat diminimalisir angka kekerasan setiap tahun (Utami, 2018). 


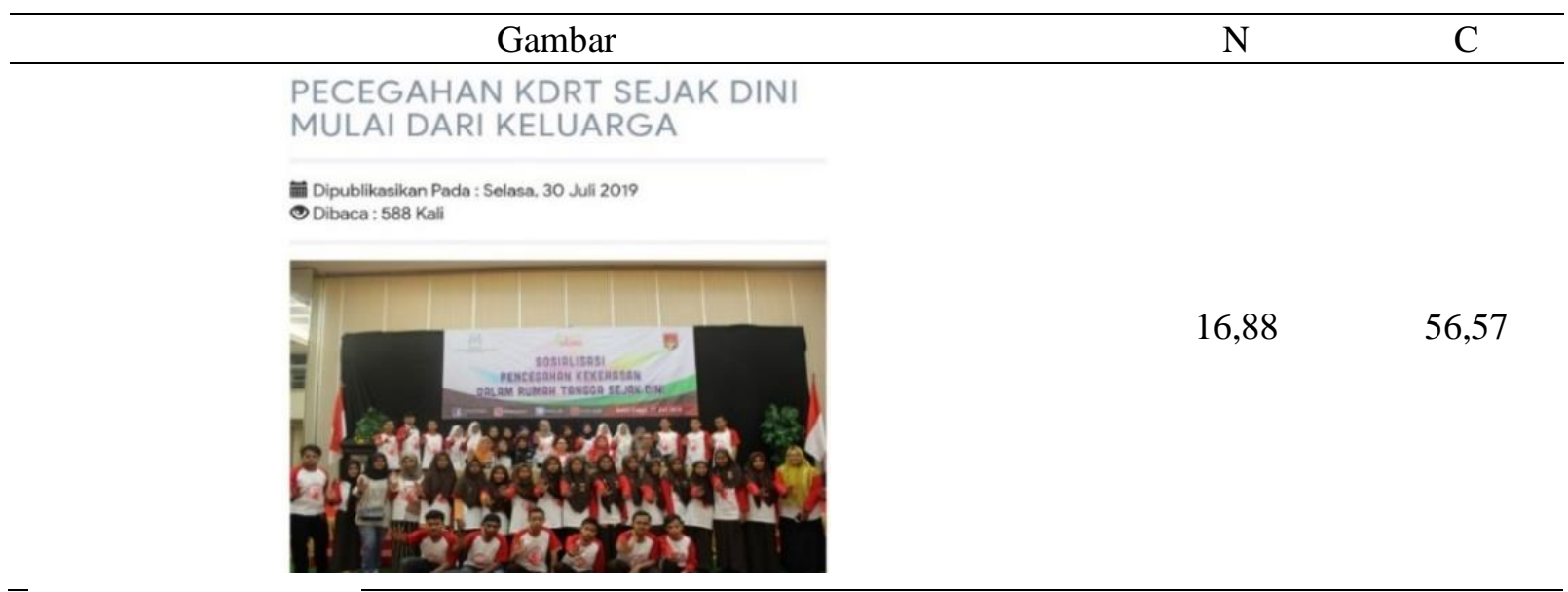

Sumber: Olahan Peneliti

Gambar 3. Artikel Ketiga

Siaran pers pada 30 Juli 2019 dengan judul "Pencegahan KDRT Sejak Dini Mulai Dari Keluarga" dibaca 588 kali. Memiliki 456 total kata yang terdiri atas 121 kata tidak dalam kategori, 77 kata termasuk dalam kategori nurturing roles, dan 258 kata termasuk dalam kategori controlling roles.

"Kekerasan Dalam Rumah Tangga (KDRT) merupakan kejadian yang merusak sendi utama ketahanan keluarga dengan korban terbanyak perempuan dan anak. Dampaknya pun juga akan terbawa dalam siklus kehidupan dan tumbuh kembang anak dalam rumah tangga. Perlu menjadi perhatian bahwa untuk mengatasi kekerasan terhadap perempuan membutuhkan upaya yang serius di bidang hukum dan budaya. Produk hukum terkait pengaturan tata kelola dan penggunaan internet harus memasukkan dimensi pencegahan kekerasan terhadap perempuan, bukan semata-mata hanya dalam konteks pornografi. Mencegah KDRT mulai dari keluarga dan anak-anak, besar harapan agar sosialisasi ini memberikan pemahaman pada generasi muda tentang potensi, pencegahan, dan dampak dari KDRT serta pemahaman tentang pentingnya ketahanan keluarga”.

Dari kutipan diatas, terlihat peran kontrol pola boundary maintanance dilakukan keluarga untuk pencegahan KDRT, yakni dengan mengendalikan lingkungan, membatasi pilihan, dan memastikan perilaku yang dimunculkan positif dan baik terhadap anak. Dengan tingginya kejadian KDRT dapat memberi dampak buruk bagi kesehatan anggota keluarga selaku korban. Dampak tersebut meliputi rasa takut, cemas, letih, kelainan, stress post traumatic, serta gangguan makan dan tidur yang merupakan reaksi panjang dari tindak kekerasan (Ramadani \& Yuliani, 2017).

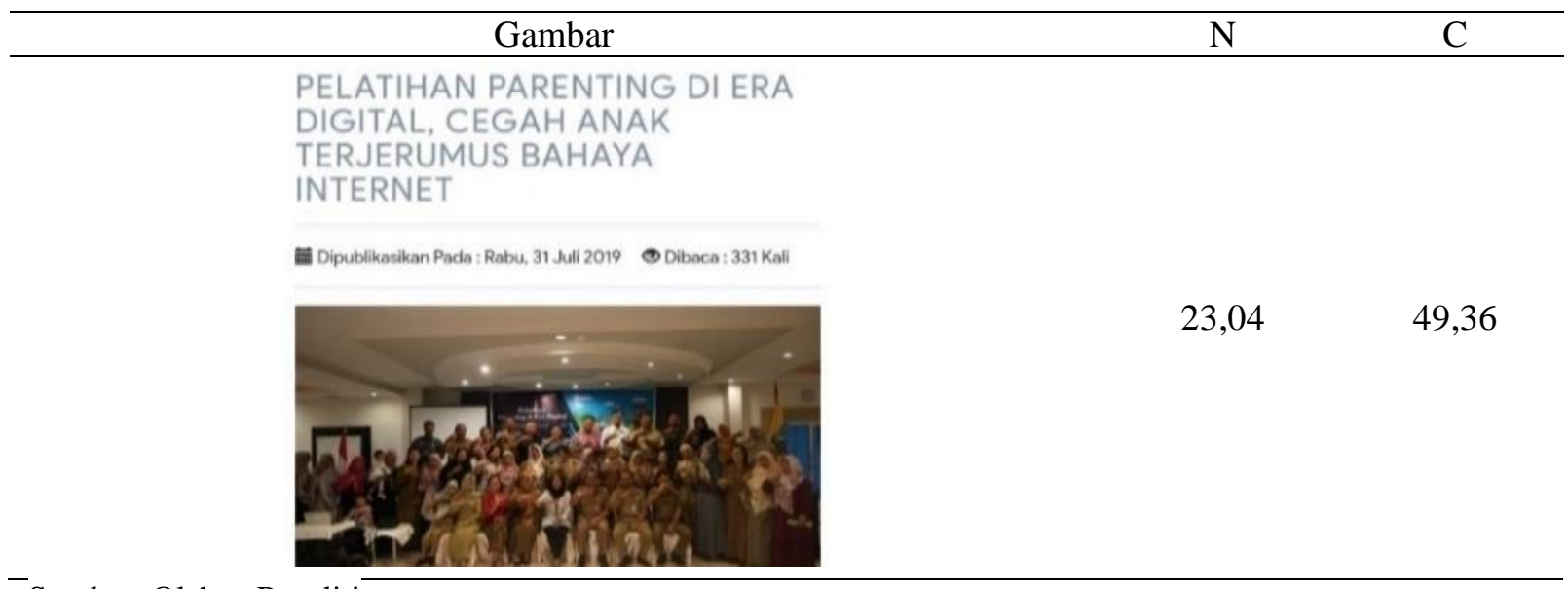

Sumber: Olahan Peneliti

Gambar 4. Artikel keempat 
Siaran pers pada 31 Juli 2019 dengan judul "Pelatihan Parenting di Era Digital, Cegah Anak Terjerumus Bahaya Internet". dibaca 311 kali. Memiliki 551 total kata yang terdiri atas 152 kata tidak dalam kategori, 127 kata termasuk dalam kategori nurturing roles, dan 272 kata termasuk dalam kategori controlling roles.

"Kementerian Pemberdayaan Perempuan dan Perlindungan Anak bekerjasama dengan organisasi perlindungan anak, 'Sejiwa' melaksanakan Pelatihan Parenting di Era Digital, Kegiatan ini bertujuan untuk mengedukasi para orangtua, tenaga pendidik, serta masyarakat dengan mendampingi anak dalam menggunakan gawai dan melindungi anak dari dampak negatif dunia digital."

Dari kutipan, dapat langsung diketahui peran kontrol lebih dominan pada artikel ini dibandingkan peran pengasuh. Pola behavior control, peran orangtua dalam upaya kontrol perilaku anggota keluarga memiliki peran menetapkan batasan serta memberikan bimbingan kepada anak sebagai anggota keluarga melalui disiplin dengan tujuan melindungi anak dari dampak negatif dunia digital. Dampak negatif media sosial yang lain adalah menciptakan jarak antara anak dan keluarga (Triastuti et al., 2017).

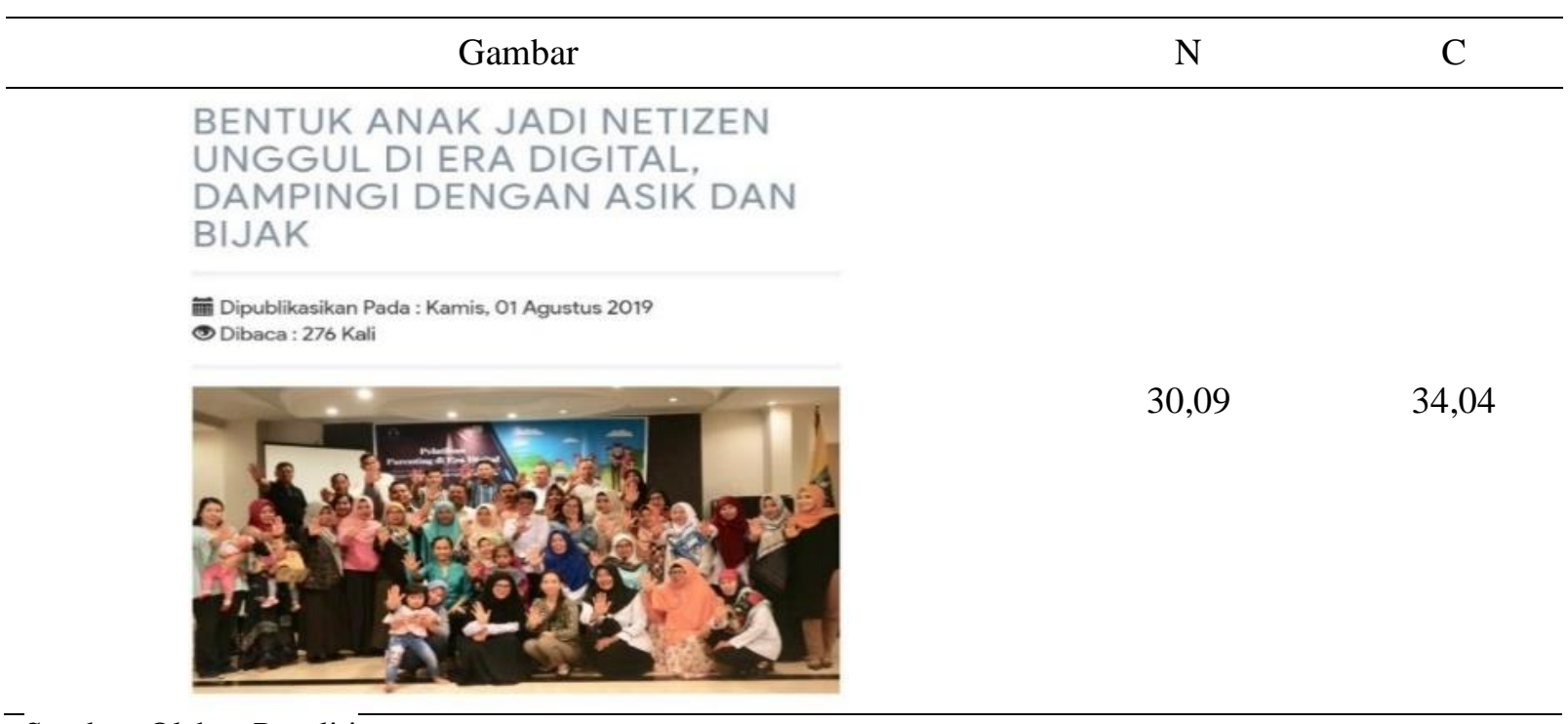

Sumber: Olahan Peneliti

Gambar 5. Artikel Kelima

Siaran pers pada 01 Agustus 2019 dengan judul "Bentuk Anak jadi Netizen Unggul di Era Digital, Dampingi dengan Asik dan Bijak" dibaca 276 kali. Memiliki 551 total kata yang terdiri atas 152 kata tidak dalam kategori, 127 kata termasuk dalam kategori nurturing roles, dan 272 kata termasuk dalam kategori controlling roles.

"Kementerian Pemberdayaan Perempuan dan Perlindungan Anak membuat berbagai kebijakan berupa pedoman, peraturan, serta menyelenggarakan beberapa kegiatan yang diharapkan secara efektif bisa direplikasikan di seluruh wilayah Indonesia. Dalam mendampingi anak di era digital, harus dilakukan dengan cara asyik dan bijak. Orangtua harus melakukan pendekatan kepada anak, mengajaknya untuk beraktivitas menikmati momen bersama, melakukan hal yang ia sukai di dunia nyata agar anak tidak larut dan berlebihan menggunakan internet. Orangtua harus bisa membangun komunikasi yang baik dengan anak secara asertif dan terkoneksi dalam berbagai situasi terkait dunia digital, seperti memuji, menegur, bernegosiasi, dan lain-lain. Kita harus menciptakan suasana ramah, hangat dan penuh cinta bersama anak agar ia tidak mencari kegiatan di luar rumah yang ancamannya lebih besar. Hadir dalam hidup anak, mau mendengarkan mereka dengan antusias, menjadi teman diskusi yang asyik. Terapkan nilai-nilai luhur pada anak seperti jujur, menghargai, ikhlas peduli, empati, bijak, cinta atau sayang pada anak."

Dalam kutipan ini didapati cara pendekatan peran keluarga yang dimulai dari kategori peran pengasuhan yaitu mengayomi, melindungi, dan bersahabat dengan anak seperti yang ditunjukkan pada 
pola health care provider untuk memperoleh kategori peran kontrol yaitu pembatasan penggunaan gadget dengan pola behavior control, perilaku berfokus pada orang tua sebagai agen sosialisasi utama untuk anak-anak dalam bertindak. Keluarga merupakan institusi yang paling penting pengaruhnya terhadap proses sosialisasi (Nugraha, 2014).

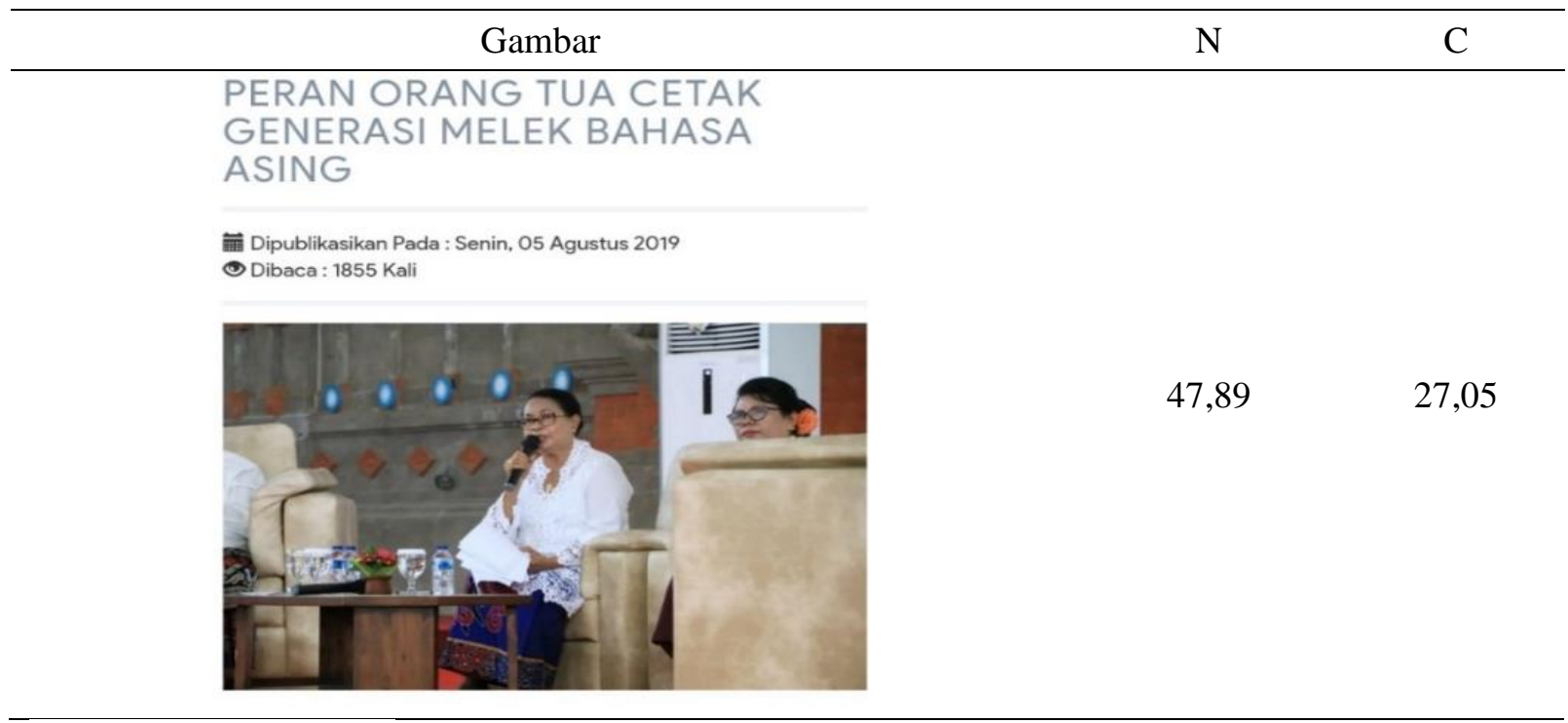

Sumber: Olahan Peneliti

Gambar 6. Artikel keenam

Siaran pers pada 05 Agustus 2019 dengan judul "Peran Orang Tua Cetak Generasi Melek Bahasa Asing" dibaca 1.855 kali. Memiliki 547 total kata yang terdiri atas 137 kata tidak dalam kategori, 262 kata termasuk dalam kategori nurturing roles, dan 148 kata termasuk dalam kategori controlling roles.

"Orang tua memainkan peran penting dalam menanamkan literasi bahasa asing dan ilmu lainnya bagi
anak - anak. Kemen PPPA yang telah bekerjasama dengan Kementerian Komunikasi dan Informatika
melalui program Internet Aman untuk Anak demi mencegah dari bahaya internet. Salah satu alasan
mengapa anak terancam bahaya internet adalah mereka diberi kebebasan yang berlebih oleh orang
tuanya dalam menggunakan teknologi. Pengembangan kompetensi global, utamanya terkait literasi
bahasa asing membutuhkan keterlibatan orang tua, terutama pada tahap awal pembelajaran. Ini
berkaitan dengan peran mereka dalam membesarkan dan mendidik anak di rumah pada tahap
pembelajaran awal, mengajarkan mereka untuk berkomunikasi secara efektif dengan sopan santun, dan
membantu anak-anak di rumah untuk mengerjakan pekerjaan sekolah. KPPPA juga telah mengambil
peran untuk meningkatkan pendidikan orang tua dalam mengasuh dan meningkatkan keterlibatan mereka
dengan anak - anaknya."

Dalam kutipan, dapat dilihat Digital native tidak hanya memiliki pengalaman baik dalam penggunaan media sosial, namun mereka juga mendapatkan pengalaman buruk yang pernah merugikan diri mereka (Supratman, 2018). Anak- anak dan remaja yang mengisi waktu luangnya dengan mengakses media sosial secara tidak sadar mengungkapkan terlalu banyak informasi tentang kehidupan pribadi mereka, Hal itu dapat menyebabkan masalah-seperti kerentanan terhadap cyberbullies (Triastuti et al., 2017).

Peran pengasuh pola Development Expert terkait peningkatan intelektual anak, dibutuhkan orang tua yang memiliki intelektual baik pula, perwujudannya di fasilitasi oleh KPPPA yang bekerja sama dengan Kementrian Komunikasi dan Informatika dengan belajar bahasa asing untuk orang tua. Peran kontrol juga mengimbangi pada pola boundary maintanance, membatasi pola perilaku anak dan aman dalam penggunaan internet (Supratman, 2018). 


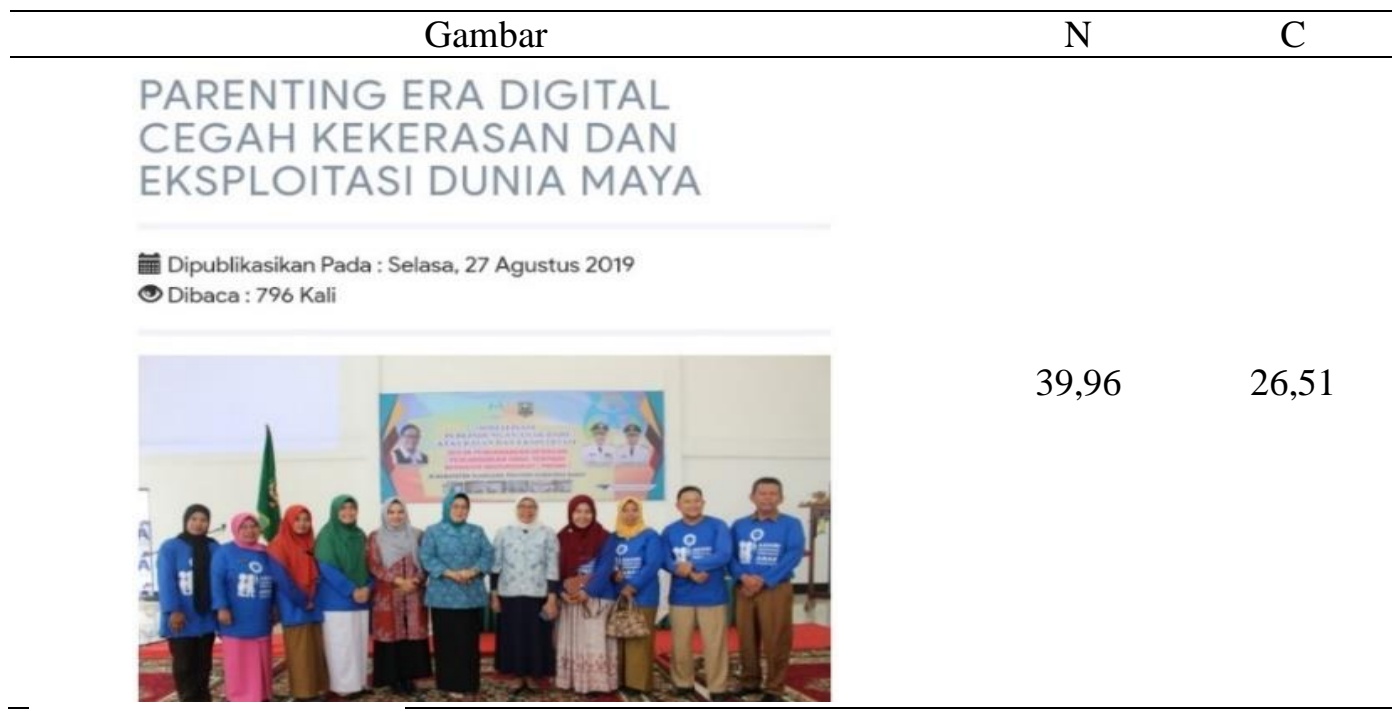

Sumber: Olahan Peneliti

\section{Gambar 7. Artikel Ketujuh}

Siaran pers pada 27 Agustus 2019 dengan judul "Parenting Era Digital Cegah Kekerasan dan Eksploitasi Dunia Maya" dibaca 796 kali. Memiliki 528 total kata yang terdiri atas 177 kata tidak dalam kategori, 211 kata termasuk dalam kategori nurturing roles, dan 140 kata termasuk dalam kategori controlling roles.

"Ketidakseimbangan pengetahuan internet yang dimiliki anak dan orangtua menyebabkan rendahnya monitoring dan pengawasan terhadap aktivitas anak di Internet. Hal ini secara tidak langsung menyebabkan anak rentan menjadi korban kekerasan dan eksploitasi di media sosial. Kementerian Pemberdayaan Perempuan dan Perlindungan Anak (KPPPA) berupaya mencerdaskan masyarakat, untuk bersama-sama melakukan deteksi dini sebagai upaya perlindungan anak, menanamkan pentingnya melindungi anak dari segala bentuk perilaku kekerasan dan eksploitasi."

Dalam kutipan ini dilihat adanya upaya organisasi untuk memberikan edukasi kepada orang tua dalam mendidik anak lebih baik lagi, serta mendeteksi gejala eksploitasi di media sosial. Peran pengasuhan dengan pola health care provider yang memastikan bahwa anggota keluarganya sehat, dan development expert yakni memberikan pembangunan fisik, sosial, emosional atau psikologi yang baik terhadap anggota keluarga. Peran kontrol yang dapat dilihat dari kutipan ini adalah behavior control, dimana orang tua mendisiplinkan anak dalam penggunaan gadget, serta boundary maintanance, berarti membatasi akses gadget anak, dan memberikan pengawasan khusus dalam setiap penggunaannya. Kebanyakan orang tua menekankan perlunya pengawasan penggunaan media sosial. Padahal penggunaan media terhitung lebih efektif dalam penerimaan informasi serta mempercepat proses edukasi (Sapoetri \& Pannindriya, 2019), ini merupakan kegiatan pengawasan adalah dengan melakukan pembatasan waktu penggunaan (Triastuti et al., 2017).

\section{KESIMPULAN}

Penelitian ini menggunakan analisis isi sistematik (Hidayat, 2015), dengan pengambilan 7 laman siaran pers menggunakan rumus analisis isi, nurturing roles dengan 4 pola didalamnya memperoleh hasil keseluruhan 242,63 dan rata-rata 35\% adanya peran pengasuhan (nurturing roles) selalu ditemukan di setiap artikel peran keluarga, sedangkan controlling roles dengan 4 pola di dalamya memperoleh hasil keseluruhan 239,25 dan rata-rata 34,1\% adanya peran kontrol (controlling roles) selalu ditemukan disetiap artikel peran keluarga. Dari kedua perolehan hasil terdapat selisih $0,03 \%$ dari kedua kategori tersebut. Hal ini menunjukkan adanya keseimbangan peran pengasuhan dan peran kontrol yang ditonjolkan oleh Humas KPPPA dalam membangun komunikasi keluarga melalui laman media daring resmi.

Metode pengukuran sifat-sifat isi yang paling banyak dipakai adalah frekuensi yang mencatat setiap kejadian dari sifat tertentu (mohajan, 2018). kategorisasi isi harus menggunakan kriteria 
tertentu. Hasil analisis haruslah menyajikan generalisasi artinya temuannya haruslah mempunyai sumbangan teoritis (Analisis Isi Pemberitaan Tentang kabupaten Garut, 2007). Menurut Holsti, Angka realibilitas minimum yang ditoleransi adalah 0,7 atau $70 \%$. Jika hasil perhitungan menunjukkan angka realibilitas (Siregar, 2013). Seperti yang diperoleh 0,03\% maka dapat disimpulkan bahwa terdapat keseimbangan antara peran pengasuhan dan peran kontrol disusun dan tonjolkan melalui strategi budaya kehumasan melalui family roles communication Le Poire dalam laman siaran pers periode Mei hingga Agustus 2019 di situs resmi KPPPA pada laman siaran. Terlihat bahwa teori family roles communication dalam situs resmi KPPPA selain memperlihatkan keseimbangan fungsi keluarga, dalam setiap kontennya pula memperlihatkan komunikasi yang dibangun sejak dini, dan memperlihatkan lingkungan keluarga yang ideal serta efektif bagi pertumbuhan setiap anggota keluarga.

Hasil yang diperoleh cukup baik melihat angka selisih yang minimum, namun apabila dilihat dari rata-rata pembaca setiap laman memperoleh angka 683 kali dibaca. Dapat dilihat bahwa tingkat populer KPPPA ditengah masyarakat kurang memperoleh atensi, sehingga perlu peningkatan kesadaran masyarakat yang mampu meningkatkan ketertarikan masyarakat tentang pentingnya peran keluarga dipahami baik peran pengasuhan ataupun kontrol.

\section{UCAPAN TERIMA KASIH}

Apresiasi setinggi-tingginya untuk semua lembaga yang berkontribusi dalam penelitian ini seperti Universitas Bunda Mulia yang bersedia terlibat secara langsung dalam proses selama penelitian ini berlangsung. Terima kasih khususnya kepada program studi Magister Ilmu Komunikasi Universitas Bunda Mulia, melalui hibah internal dosen Universitas Bunda Mulia yang menunjang operasionalisasi penelitian ini dari awal sampai dengan publish, serta sangat berkontribusi menyalurkan pesan mengenai peran pentingnya pengasuhan dan kontrol keluarga pada masyarakat Indonesia. Ucapan terima kasih untuk panitia Negeri Komunikasi, seminar nasional dan call for paper Komunikasi, Literasi, Media, dan Budaya. Terima kasih untuk Jurnal Komunikasi Pembangunan Institut Pertanian Bogor (JKMP IPB) yang telah menerima penelitian ini, sehingga dapat publish dan diharapkan penelitian dengan tema pendekatan budaya dalam praktik kehumasan dapat menjadi khasanah yang berguna bagi penelitian ke depannya.

\section{DAFTAR PUSTAKA}

Agung, A., Prihandari, I., \& Danadharta, I. (2019). KEBERLANJUTAN JURNALISTIK SEHAT DI ERA KONVERGENSI DARING SUARASURABAYA.NET DENGAN PENDEKATAN ENGAGEMENT PYRAMID. Bricolage: Jurnal Magister Ilmu Komunikasi, 5(2), 177-194.

Campbell, D. F., \& Kachik, C. J. (2017). Introduction to special issue. Community College Journal of Research and Practice, 25(9), 667-673. https://doi.org/10.1080/106689201753199599

Edi Setyawan dan Zainal Arifin. (2016). ANALISIS KONTEN KURIKULUM JURUSAN PENDIDIKAN TEKNIK NEGERI. Jurnal Pendidikan Teknik Otomotif, XIV(2), 38-44.

Evelyn. (2018). Komunikasi Interpersonal Antara Anak Agnostik dengan Orang Tua Beragama. Jurnal E-Komunikasi, 6(1), 1-10.

Handayani, D. N., Sudrajat, R. H., \& Imran, A. I. (2015). ANALISIS ISI VISUAL IKLAN DAN STRATEGI KREATIF KATEGORI PRINT AD PEMENANG GOLD, SILVER, DAN BRONZE CITRA PARIWARA 2015. Jurnal Ilmiah Komunikasi, 6(1), 1-14.

Hidayat, T. W. (2015). Analisis Berita Kesehatan di Media Massa terhadap Pelayanan Publik. Jurnal Simbolika, 1(September), 137-153.

I. Satriani, P. Muljono, R. W. E. L. (2011). Komunikasi Partisipatif Pada Program Pos Pemberdayaan Keluarga. Komunikasi Pembangunan, 9(2), 17-27. 
Junaidi, A. (2017). Media dan Keberagaman: Analisis Pemberitaan Media Daring Seputar Pemilihan Kepala Daerah DKI Jakarta. Jurnal Muara Ilmu Sosial, Humaniora, Dan Seni, 1(1), 329-337. https://doi.org/10.24912/jmishumsen.v1i1.373

Kriyantono, R., \& Sa'diyah, H. (2018). Kearifan Lokal dan Strategi Komunikasi Public Relations di BUMN dan Perusahaan Swasta. Jurnal ILMU KOMUNIKASI, 15(2), 171-188. https://doi.org/10.24002/jik.v15i2.1480

Kumalaningtyas, N., \& Sadasri, L. M. (2018). Citra Tubuh Positif Perempuan Dalam Iklan Video Digital (Studi Femvertising Pada Iklan Dove Real Beauty). Diakom : Jurnal Media Dan Komunikasi, 1(2), 62-73. https://doi.org/10.17933/diakom.v1i2.19

Marta, R. F. (2003). REFLEKSI HIBRIDITAS BUDAYA DALAM PANCASILA PADA REALITAS DAN MEDIA SEBAGAI IDENTITAS BANGSA. Bricolage: Jurnal Magister Ilmu Komunikasi, 3(1), 1-12.

Marta, R. F., Fernando, J., \& Simanjuntak, R. F. (2019). EKSPLIKASI KUALITAS KONTEN PERAN KELUARGA PADA INSTAGRAM @ KEMENPPPA. Journal of Communication Ettisal, 4(2).

MOHAJAN, H. K. (2018). Qualitative Research Methodology in Social Sciences and Related Subjects. Journal of Economic Development, Environment and People, 7(1), 23. https://doi.org/10.26458/jedep.v7i1.571

Nihayah, I. (2018). Analisis peran keluarga dalam membentuk karakter anak. Jurnal Pendidikan Islam, 6, 31-56.

Nugraha, A. R. (2014). Fungsi Humas Pemerintah Kabupaten Sumedang Dalam Mengkampanyekan Sumedang Sebagai Puseur Budaya Sunda (Spbs). Journal Edutech, 13(1), 34. https://doi.org/10.17509/edutech.v13i1.3220

Nugroho, W., \& Saleh, F. (2012). Perancangan Media Komunikasi Berbasis Web Untuk Pembelajaran. Jurnal Sistem Informasi, 5(2), 100. https://doi.org/10.21609/jsi.v5i2.268

Perdana. (2018). RENCANA STRATEGIS KEMENTERIAN PEMBERDAYAAN PEREMPUAN DAN PERLINDUNGAN ANAK TAHUN 2015-2019. Journal of Chemical Information and Modeling, 53(9), 1689-1699. https://doi.org/10.1017/CBO9781107415324.004

Pramudya. (2014). Mencari akar penyebab kekerasan dalam rumah tangga terhadap perempuan tionghoa di jawa tengah. Jurnal Dinamika Hukum, 14(23), 151-161.

Rahmawati, D., \& Anindhita, W. (2016). POTENSI MEDIA DARING MENCIPTAKAN KOMUNITAS INFORMASI. Jurnal Bakrie, 730-736.

Ramadani, M., \& Yuliani, F. (2017). Kekerasan Dalam Rumah Tangga (Kdrt) Sebagai Salah Satu Isu Kesehatan Masyarakat Secara Global. Jurnal Kesehatan Masyarakat Andalas, 9(2), 80. https://doi.org/10.24893/jkma.v9i2.191

Sapoetri, A., \& Pannindriya, T. (2019). GELIAT INTERAKSI SOSIAL DOKTER MASA KINI MELALUI MEDIA SOSIAL INSTAGRAM. Bricolage: Jurnal Magister Ilmu Komunikasi, 5(2), 121-140.

Sari, A., Hubeis, A. V. S., Mangkuprawira, S., \& Saleh, A. (2010). Pengaruh Pola Komunikasi Keluarga dalam Fungsi Sosialisasi Keluarga terhadap Perkembangan Anak. Jurnal Komunikasi Pembangunan, 08(2).

Sasongko, Y. P. D., \& Marta, R. F. (2018). Ekspresi identitas melalui relasi ayah dan anak pada iklan youtube grab official. Bricolage: Jurnal Magister Ilmu Komunikasi, 4(2), 118-132.

Satya Yoga, D., Suarmini, N. W., \& Prabowo, S. (2015). Peran Keluarga Sangat Penting dalam Pendidikan Mental, Karakter Anak serta Budi Pekerti Anak. Jurnal Sosial Humaniora, 8(1), 46. https://doi.org/10.12962/j24433527.v8i1.1241

Setiadi, A. A. (2010). Analisis Isi Implementasi Elemen Competitive Identity pada Nation Branding “ 
Imagine Your Korea " di Facebook Pendahuluan. Jurnal E-Komunikasi, 5(1).

Analisis Isi Pemberitaan Tentang kabupaten Garut, 53 Universitas Padjajaran 1689 (2007). https://doi.org/10.1017/CBO9781107415324.004

Siregar, A. A. (2013). Media dan Kekerasan Terhadap Anak (Analisis Isi Berita Kekerasan Terhadap Anak dalam Harian Medan Pos). Jurnal Flow, 66, 37-39.

Suarmini, N. W., Rai, N. G. M., \& Marsudi, M. (2016). Karakter Anak Dalam Keluarga Sebagai Ketahanan Sosial Budaya Bangsa. Jurnal Sosial Humaniora, 9(1), 78. https://doi.org/10.12962/j24433527.v9i1.1280

Supratman, L. P. (2018). Penggunaan Media Sosial oleh Digital Native. Jurnal ILMU KOMUNIKASI, 15(1), 47-60. https://doi.org/10.24002/jik.v15i1.1243

Triastuti, E., Andrianto, D., \& Nurul, A. (2017). Kajian Dampak Penggunaan Media Sosial Bagi Anak Dan Remaja. In Puskakom UI.

Utami, P. N. (2018). Pencegahan Kekerasan Terhadap Anak dalam Perspektif Hak Atas Rasa Aman Di Nusa Tenggara Barat. Jurnal HAM, 9(1), 1. https://doi.org/10.30641/ham.2018.9.1-17

Wahjudi, S. (2018). Relasi Dan Peran Aktor Dalam Pemanfaatan Rptra Kelurahan Pejagalan Jakarta Utara. Bricolage: Jurnal Magister Ilmu Komunikasi, 4(01), 1-22. https://doi.org/10.30813/bricolage.v4i01.1064

Wiratmo, B. L., Irfan, N., \& Kuwatono. (2017). Situs resmi Pemerintah Daerah Sebagai Sarana Online Public Relations. Jurnal ASPIKOM, 3(2), 326-339.

Yulion, M. M. (2013). MEMAHAMI PENGALAMAN KOMUNIKASI PENGASUHAN ANAK DALAM EXTENDED FAMILY. Jurnal Interaksi Online, 66, 37-39.

Yuningsih, A. (2005). REIDENTIFIKASI BUDAYA ORGANISASI MELALUI PENDIDIKAN KEHUMASAN. Jurnal Mimbar, XX(4), 478-492.

Yunita, N. P., \& Aprianto, R. D. (2018). Kondisi Terkini Perkembangan Pelaksanaan E-Government Di Indonesia : Analisis Situs resmi. SENTIKA, 2018(Sentika), 329-336. 